\title{
The Transmission Effects of the U.S. Monetary Policy Shocks in the Korean Output and Trade: A SVAR Approach
}

\author{
Shiyou Zhu', Seo-Hyeong Lee ${ }^{2, *}$ \\ ${ }^{1}$ School of Finance, Anhui University of Finance and Economics, Bengbu, China \\ ${ }^{2}$ Department of International Commerce, Keimyung University, Daegu, Korea
}

Email address:

zhushiyou2005@163.com (Shiyou Zhu),Minhwan2@daum.net (Seo-Hyeong Lee)

${ }^{*}$ Corresponding author

\section{To cite this article:}

Shiyou Zhu, Seo-Hyeong Lee. The Transmission Effects of the U.S. Monetary Policy Shocks in the Korean Output and Trade: A SVAR Approach. International Journal of Business and Economics Research. Vol. 5, No. 4, 2016, pp. 127-134. doi: 10.11648/j.ijber.20160504.18

Received: June 28, 2016; Accepted: August 4, 2016; Published: August 8, 2016

\begin{abstract}
This paper estimates the bilateral trade balance and real output growth rate in Korea to identify the transmission effects of the U.S. monetary policy shocks and then presents a statistical decomposition of the rate through a structural VAR using monthly data from January 1999 to December 2014. Results showed that the Korean trade balance is negatively affected by the U.S. monetary shocks through the exchange rate channel because of the most direct policy transmission channels is the international capital flows and exchange rate in the short-term. On the other hand, domestic real output is positively affected by the external monetary policy shocks over time. Thus the estimations of the trade balance and output growth in Korea suggest that, over the sample period, real economy in the small open economy influenced by the monetary policy shocks in the large country such as the U.S. Therefore, it is important to respond appropriately to changes in exchange rates in order to reduce unexpected negative influence from the external shocks.
\end{abstract}

Keywords: Monetary Policy, Transmission Effects, Trade Balance, Real Output, Structural VAR, Variance Decomposition

\section{Introduction}

Monetary policy is broadly used by central banks to achieve stabilization of the value of money and sustaining high economic growth. Such monetary policy would affect other related economies as an external shock by international trade and capital flows. Since the Global Crisis in 2008, the U.S. Federal Reserve sharply cut its target for the federal funds rate which is the primary tool of the U.S. monetary policy to a range between 0 percent and 0.25 percent by quantitative easing. In the globalized world, monetary expansion in a large economy like the U.S. decreases real interest rates around the world and promotes aggregate demand worldwide. So the transmission effects of the external monetary policy shocks to other economies have been demonstrated in the theoretical literature. Nevertheless, we cannot deny the possibility of those empirical effects is varying in the direction and the strength of its impacts across economies, periods, and empirical methodologies.

Many empirical studies, such as Sims [16], Grilli and
Roubini [6], Kim and Roubini [8], Neril and Novili [15], Li and Liang [10], Mirkov [13], Precious and Palesa [15], Barakchian [2], Bowman, et al. [3], Lee and Zhu [9] have investigated the international transmission mechanism by using VAR models of developed and developing economies. Kim [7], for example, suggested that U.S. monetary policy shocks on the output of the developed countries had a positive effect. Mackowiak [12] showed the monetary policy shocks of the developed countries had a negative output effect for the emerging economies. He used the structural VAR approach to study the effects of external shock on eight emerging economies. He found that the U.S. monetary shock affects the real output and price levels in emerging economies even more strongly than the real output and price levels in the U.S.

Recently Barakchian [2] showed that the responses of the Canadian macro variables to the US monetary policy shock are very similar to the responses of the US macro variables to the same shock. He also showed that interest rate-path-through is the major mechanism by which US monetary policy shocks are transmitted into the Canadian economy. 
As such, it is meaningful and valuable to understand the effects of external monetary aggregates shocks in the macroeconomic transmission mechanism in the trade-dependent economies. Especially, due to the different economic conditions, it can be assumed that the transmission effect of external monetary policy shocks is country specific. Thus this paper examines the transmission effects of monetary policy shocks in the U.S. on Korea's trade balance and output growth. In this regard, the main research question is that is there a significant transmission effect of external monetary aggregates shocks to domestic interest rate, exchange rate, trade, and output?

The objective of this study is to examine the mechanism linking the changes in the external monetary policy shocks to the domestic real economies such as output and trade in globalized economies using a Structural Vector Autoregression (SVAR) methodology. A SVAR model makes the identification of structural shocks possible while letting the different variables play off of each other. Moreover, SVAR relies on moving average representation and studies the system dynamics in terms of impulse responses triggered by each independent structural shock (Stock and Watson [17]). Therefore, we have examined the effects of its external shocks through impulse response and variance decomposition analysis based on SVAR using monthly data for Korea from the period 1999:1 to $2014: 12$. The details are presented in Section II.

Results showed that trade balance grows worse significantly and domestic currency appreciated following monetary expansion shocks of the U.S., but domestic real output is positively affected by the external monetary policy shocks over time. These results imply that it is important to respond appropriately to changes in exchange rates in order to reduce unexpected negative influence due to the external shocks especially in the small open economies like Korea.

The remainder of the paper is organized as follows. Section II describes the empirical model for analysis and introduces the sources and nature of the data used in the empirical analysis. Section III introduces the SVAR methodology and identification scheme. Section IV reveals the model diagnostics and the different empirical results of impulse response function and variance decomposition. The conclusion follows in the last section.

\section{Empirical Model and Methodology}

\subsection{Empirical Model}

Although monetary policy is thought to be neutral in the long term, it must affect macroeconomic variables in the short term. Thus international transmission mechanism of external monetary policy shocks is interesting issue to know how a country's economic variables respond to the exogenous shocks. Theoretically, monetary expansion in a large economy, for example, decreases real interest rates around the world and promotes aggregate demand worldwide.

In general, quantitative easing starts a temporary fall in the domestic interest rate with the resulting loss of foreign exchange reserves. Over time, the impacts of monetary shocks would appear to be inflation and output growth. Such puzzles basically consist of price, interest rate, exchange rate, and output puzzles where the interest rate decreases, price increases, domestic currency depreciates following monetary expansion shock. In the empirical literatures, for instance, Sims [16] demonstrated that interest rate innovations partly reflect inflationary pressures which cause an increase of price level. For this reason, many empirical studies such as Gorden and Leeper [5], Christiano, et al. [4]), etc. include inflationary expectation as a proxy of the inflationary pressures in the VAR model. In addition, at the same time, the impact of monetary shocks is spread abroad with a time lag. Therefore, the extended models that include the additional variables, such as foreign interest rate, exchange rate, trade balance, and output.

Our SVAR model is structured as follows. The monetary aggregates over the period of analysis capture quantitative easing. Given that interest rates are at low levels, central banks have introduced quantitative easing by central banks in an attempt to increase lending and liquidity. In this paper, Federal Funds rate are used to represent monetary policy for the US economies. Specifically, the macro financial structure of each economy is characterized by using a set of four domestic endogenous variables and three foreign variables: the annual growth in domestic nominal monetary aggregate $(K M 2)$, nominal exchange rate $(E X R)$, measured as the value of Korean won to the US dollar, bilateral trade balance $(K T B)$, real output (KPG), foreign monetary policy indicator (FFR), monetary aggregates (UM2) and real output $(U P G)$, respectively.

\subsection{Estimation Methodology}

Methodologically, a seven variable structural vector autoregression (SVAR) model is used to examine the effects of external monetary policy shocks, both contemporaneous and lagged, on trade and output by analyzing impulse response function (IRF) and variance decomposition (VDC). To understand the model it will be useful to summarize the SVAR modeling process. Consider an open economy which has $K$ -dimensional time series $y_{t}, t=1,2, \cdots, T$, described by the following structural form of equation with the order $p$ :

$$
\mathrm{A}(\mathrm{L}) y_{t}=v_{t}
$$

In the structural equation, $y_{t}$ is a $(K \times 1)$ vector of endogenous variables of interest, $A(L)$ ( $=A_{0}-A_{1} L-A_{2} L^{2}-\cdots-A_{p} L^{p}$ ) is the autoregressive lag order polynomial and is decomposed into $A_{0}$ and $A^{0}(L)$. The notation $A_{0}\left(=A_{1,2, \cdots, p}\right)$ is a $K \times K$ non-singular matrix that characterizes the contemporaneous relationships among $y_{t} \mathrm{~s}$, and $A^{0}(L)$ is the coefficients of the lagged structural variables. $v_{t}$ is a $(K \times 1)$ vector of mean zero serially uncorrelated error term, also referred to as a structural 
innovation or shock, and variance-covariance matrix of the structural innovation term is typically normalized as $\operatorname{var}\left(v_{t}\right)=E\left(v_{t} v_{t}^{\prime}\right)=\Omega=I$, where the diagonal elements of $\Omega$ stand for the variance of structural innovation and the off diagonal elements are restricted to zero. Equation (1) can be described as following equation (2).

$$
A_{0} y_{t}=-A^{0}(L) y_{t}+v_{t}
$$

In order to allow for any estimation in the structural model we first need to derive its reduced form representation. To derive the reduced form VAR model, pre-multiply both sides of structural VAR equation (2) by $A_{0}^{-1}$ :

$$
A_{0}^{-1} A_{0} y_{t}=-A_{0}^{-1} A^{0}(L) y_{t}+A_{0}^{-1} v_{t}
$$

Equation (3) is the reduced form of structural system can be represented as:

$$
B(L) y_{t}=\varepsilon_{t}, y_{t}=B_{1} y_{t-1}+\cdots+B_{p} y_{t-p}+\varepsilon_{t}
$$

where, $B(L)\left(=I-B_{1} L-B_{2} L^{2}-\cdots-B_{p} L^{p}=-A_{0}^{-1} A^{0}(L)\right)$ denotes the autoregressive lag order polynomial and $\varepsilon_{t}$ ( $\left.=A_{0}^{-1} v_{t}\right)$ is a reduced form residual vector and have covariance matrix $\Sigma=E\left(\varepsilon_{t} \varepsilon_{t}^{\prime}\right)$, is a positive definite matrix and shocks are linearly independent. These show the relationships between the structural and reduced form coefficients and disturbances, respectively. Hence, the variance of $\varepsilon_{t}$ is:

$$
E\left(\varepsilon_{t} \varepsilon_{t}^{\prime}\right)=A_{0}^{-1} E\left(v_{t} v_{t}^{\prime}\right) A_{0}^{-1} \text { or } \Sigma=A_{0}^{-1} \Omega A_{0}^{-1}
$$

In addition, the estimation of structural parameters requires the imposition of restrictions on the elements of matrix. Following Amisano and Giannini [1] structural equation can also be expressed as $A_{0} v_{t}=B_{0} \varepsilon_{i}$, where $A_{0}$ includes the structural contemporaneous coefficients and $B_{0}$ is a diagonal matrix containing their reduced form estimates. The SVAR can be exactly identified by constructing $A_{0}$ to be lower triangular matrix with appropriate orderings. $A_{0}$ is identified through the unrestricted covariance matrix of the reduced form and the diagonal covariance matrix of the structural form, $\Omega=E\left(v_{t} v_{t}^{\prime}\right)$, as in equation (5).

Since the primary interest of this study in short and medium term responses, contemporaneous restrictions on the $A_{0}$ matrix is used to identify the shocks like those shown in the following matrix format (6). We have obtained the estimates of $\Omega$ and $A_{0}$ matrices with the help of sample estimates of $\Sigma$ matrix using the MLE method. In the equation (5), $\Omega$ contains $\left(K^{2}+K\right)$ free parameters to be estimated. So at least $\left(K^{2}+K\right) / 2$ restrictions are needed to recover the structural form parameters from reduced form VAR. Finally, identified the structural disturbances from the estimated reduced form residual error terms by imposing additional zero restrictions on the coefficient matrix $A_{0}$ based on existing theory and model preferences. In this study, that is, the shock identification scheme is based on a generalized method with non-recursive structures, which impose restrictions only on contemporaneous structural parameters. While the Cholesky decomposition is commonly used identification approach, there is a limit that the ordering of variables changes the estimation results. The basic identification strategy on a model of the trade in turn was based on economic theory and Granger cause. The first three rows in equation (6) measure the external pressure on the domestic economy from the U.S. monetary policy shocks, where FFR, UM2, UPG, KM2, $E X R K T B$ and $K P G$ are the structural disturbances.

$\left[\begin{array}{c}v_{t}^{F F R} \\ v_{t}^{U M 2} \\ v_{t}^{U P G} \\ v_{t}^{K M 2} \\ v_{t}^{E X R} \\ v_{t}^{K T B} \\ v_{t}^{K P G}\end{array}\right]=\left[\begin{array}{ccccccc}1 & 0 & 0 & 0 & 0 & 0 & 0 \\ a_{21} & 1 & a_{23} & 0 & 0 & 0 & 0 \\ a_{31} & a_{32} & 1 & 0 & 0 & 0 & a_{37} \\ a_{41} & 0 & 0 & 1 & 0 & a_{46} & a_{47} \\ a_{51} & a_{52} & a_{53} & a_{54} & 1 & a_{56} & a_{57} \\ 0 & a_{62} & a_{63} & a_{64} & a_{65} & 1 & a_{67} \\ 0 & 0 & a_{73} & 0 & a_{75} & 0 & 1\end{array}\right]\left[\begin{array}{c}\varepsilon_{t}^{F F R} \\ \varepsilon_{t}^{U M 2} \\ \varepsilon_{t}^{U P G} \\ \varepsilon_{t}^{K M 2} \\ \varepsilon_{t}^{E X R} \\ \varepsilon_{t}^{K T B} \\ \varepsilon_{t}^{K P G}\end{array}\right]$

Based on the theoretical frameworks in Section II, the exchange rate is ordered in the fifth place, followed by Trade balance and output growth. The change in the exchange rate is affected by the U.S. monetary shocks and domestic monetary aggregates. Trade balance is also affected by exchange rate and monetary aggregates. Consequently, it is sensible to allow for other variables below exchange rate, especially trade balance, to be affected by exchange rate shock. We impose restrictions on parameters $a_{61}, a_{71}, a_{42}, a_{72}, a_{43}, a_{74}$, $a_{76}=0$ because bilateral trade balance and output growth will not be directly affected by foreign exchange rate shocks. Eventually, trade is assumed to be affected by all the structural shocks in the system.

\section{Estimation Results}

\subsection{Data Description}

Table 1. Definitions of Variables.

\begin{tabular}{ll}
\hline Notation & Definition \\
\hline Foreign & \\
$F F R$ & Growth of effective federal funds rate \\
$U M 2$ & Annual growth of the U.S. M2 money stock \\
$U P G$ & Annual growth of the U.S. real industrial production \\
Domestic & \\
$K M 2$ & Annual growth of Korean M2 money stock \\
$E X R$ & Annual growth of nominal won-dollar exchange rate \\
$K T B$ & Annual growth of bilateral trade balance \\
$K P G$ & Annual growth of Korean real industrial production \\
\hline
\end{tabular}

For empirical analysis, we used monthly data from 1999:1 to 2014:12 in order to capture the effects of changes in external monetary shocks that could potentially influence the domestic economy. All the raw data come from the Federal Reserve Economic Data (FRED) of the Federal Reserve Bank of St. Louis. The data consists of the U.S. and Korean monetary aggregates and industrial production indexes, short-term interest rate, exchange rate and trade balance. Table 1 shows the definitions of variables. The external 
variables are the U.S. federal funds rate and monetary aggregate M2. The domestic variables for Korea are the monetary aggregate M2 in U.S. dollars, bilateral trade balance, the industrial production and the nominal exchange rate, respectively.

In line with the treatment variable, FFR represent the U.S. federal funds rate, $U M 2$ represent nominal monetary aggregates M2 of the United States, UPG represent the U.S. real output, EXR represent the U.S. nominal exchange rate against the U.S. dollar, KTB represent the Korea-U.S. bilateral trade balance, $K M 2$ represent monetary aggregate M2 of Korea, KPG represent Korea's real output. Moreover, all the data series are seasonally adjusted using the census $\mathrm{X}-12$ approach. Also include a dummy variable of the period between July 2007 and June 2008, as founded that the extreme volatility experienced over this short period when the crisis period.

Figure 1 shows the trend of variables change over the period. As expected, there has been a big change in all cases during the global financial crisis in 2008. In Figure 1 the U.S. M2 growth rate is strongly upward after the global crisis, but the behavior of the U.S. interest rate and output growth rate are strongly downward over the period. It implies that monetary aggregates play a large role on interest rate and output. Korea's M2 and exchange rate start strongly upward without delay after the U.S. monetary policy shock. On the other hand, Korea's bilateral trade balance and output growth rate have a latent period instead of a change along with the U.S. monetary policy shock.

Before modeling monetary transmission in a VAR framework, present the results of correlation analysis of variables and the unit-root tests on monthly data in Tables 2 and 3, respectively. According to Table 2, while the positive correlations between the U.S. and Korean output growth rates, exchange rate and trade balance were strong, the negative correlation are appeared between the U.S. interest rate and monetary aggregates, exchange rate, and Korea's trade balance. In addition, a strong positive correlation was found between the U.S. and Korean output growth rates, implying that Korean economic growth appear to be heavily dependent on the U.S. economic growth.

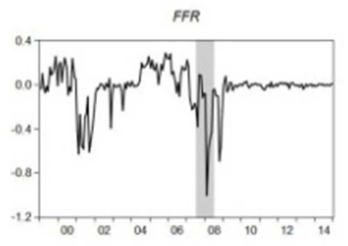

KM12

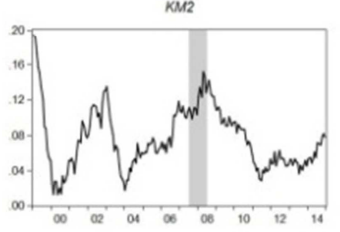

KPG

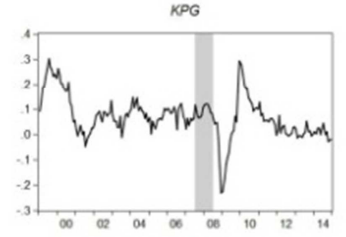

UM2

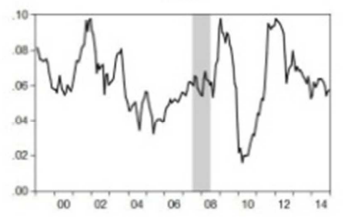

EXR
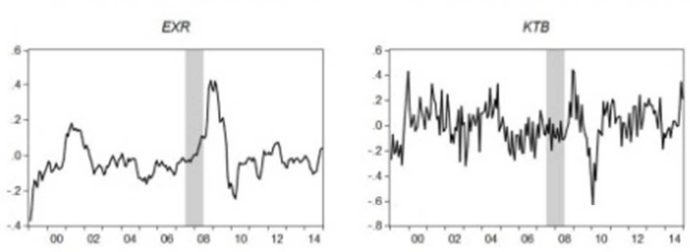

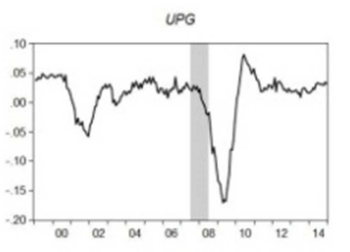

kT

$$
\text { (n) }
$$


Table 3. Results of Unit Root and LR Tests.

\begin{tabular}{llllllll}
\hline \multicolumn{6}{c}{ Unit Root Tests } & \multicolumn{6}{l}{ LR Tests } \\
\hline & ADF & PP & $\mathbf{H}_{\mathbf{0}}$ & $\mathbf{H}_{\mathbf{1}}$ & LR & AIC & SC \\
\hline FFR & $-5.98^{* * *}$ & $-5.83^{* * *}$ & $\mathrm{p}=0$ & $\mathrm{p}=1$ & 2059.7 & -30.91 & $-29.84^{*}$ \\
UM2 & $-3.70^{* * *}$ & $-2.98^{* *}$ & $\mathrm{p}=1$ & $\mathrm{p}=2$ & 159.08 & -31.30 & -29.40 \\
UPG & $-4.32^{* * *}$ & $-2.81^{*}$ & $\mathrm{p}=2$ & $\mathrm{p}=3$ & 86.64 & -31.31 & -28.57 \\
KM2 & $-3.51^{* * *}$ & $-4.08^{* * *}$ & $\mathrm{p}=3$ & $\mathrm{p}=4$ & 126.80 & -31.58 & -28.01 \\
EXR & $-3.10^{* *}$ & $-3.19^{* *}$ & $\mathrm{p}=4$ & $\mathrm{p}=5$ & 70.85 & -31.52 & -27.13 \\
KTB & $-4.21^{* * *}$ & $-8.33^{* * *}$ & $\mathrm{p}=5$ & $\mathrm{p}=6$ & 57.56 & -31.40 & -26.18 \\
KPG & $-2.73^{*}$ & $-3.17^{* *}$ & $\mathrm{p}=6$ & $\mathrm{p}=7$ & 88.69 & -31.52 & -25.46 \\
& & & $\mathrm{p}=7$ & $\mathrm{p}=8$ & 93.30 & -31.71 & -24.82 \\
& & & $\mathrm{p}=8$ & $\mathrm{p}=9$ & 53.42 & -31.62 & -23.90 \\
& & & $\mathrm{p}=9$ & $\mathrm{p}=10$ & 65.54 & -31.65 & -23.10 \\
& & & $\mathrm{p}=10$ & $\mathrm{p}=11$ & 45.75 & -31.55 & -22.17 \\
& & $\mathrm{p}=11$ & $\mathrm{p}=12$ & $76.90^{*}$ & $-31.76^{*}$ & -22.17 \\
\hline
\end{tabular}

Notes: 1) $*, * *, * * *$ indicate significance at $10 \%, 5 \%$, and $1 \%$ level, and MacKinnon [11] one-sided $1 \%, 5 \%$, and $10 \%$ critical values are $-3.46,-2.88$, -2.57 , respectively.

2) Entries are t-statistics and lag length of dependent variable as explanatory variable are selected by SIC (Schwarz Information Criterion), the results are including constant in test equation.

3) The values of likelihood ratio to test lag length are following $\chi^{2}$ distribution, * indicates lag order selected.

\subsection{Reduced Form VAR Diagnostics}

We estimated the reduced form VAR model with 12 lags, as suggested by the LR test results and AIC criterion in Table 3. Furthermore, the VAR model includes exogenous variables for the global financial crisis dummy and an intercept. Financial crisis dummy variable represents the period from July 2007 to June 2008 period.

In addition, the standard reduced form VAR assumes that the residuals are serially uncorrelated. So the VAR residual serial correlation based on the LM test up to 12 lags and normality test are also conducted. The results in Table 4 indicate that the reduced form VAR contains serially correlated residuals in most cases because the null hypothesis of no serial correlation at each lags is rejected.

Table 4. Diagnostic Tests of the Residual Serial Correlation and Normality.

\begin{tabular}{llllll}
\hline \multicolumn{2}{l}{ Residual Serial Correlation Test } & \multicolumn{4}{l}{ Residual Normality Test } \\
\hline Lag & LM & Prob. & Component & J-B & Prob. \\
\hline 1 & 76.853 & 0.007 & 1 & 1182.082 & 0.000 \\
2 & 68.349 & 0.035 & 2 & 32.510 & 0.002 \\
3 & 101.514 & 0.000 & 3 & 57.567 & 0.000 \\
4 & 55.836 & 0.234 & 4 & 5.904 & 0.052 \\
5 & 80.199 & 0.003 & 5 & 12.794 & 0.002 \\
6 & 64.142 & 0.072 & 6 & 0.400 & 0.819 \\
7 & 76.959 & 0.007 & 7 & 2.954 & 0.228 \\
8 & 77.919 & 0.005 & Joint & 1294.211 & 0.000 \\
9 & 66.695 & 0.047 & & & \\
10 & 57.161 & 0.198 & & & \\
11 & 43.389 & 0.699 & & & \\
12 & 239.682 & 0.000 & & & \\
\hline
\end{tabular}

Notes: LM represents the statistics of VAR residual serial correlation LM test statistics and probabilities from chi-square with 49 degrees of freedom. J-B denotes Jarque-Bera statistics to whether residuals are multivariate normal or not.

Then VAR Granger causality test (block exogeneity test) is conducted to look at whether the lag of any variable's Granger cause any other variable in the system. It is a bilateral test as to whether the lags of the excluded variable affect the endogenous variable. As shown in Table 5, the U.S. output growth and the change of exchange rate, the null hypothesis is rejected. These results imply that our ordering of the endogenous variables in a SVAR framework does not matter and also appropriate restrictions are imposed.

Table 5. VAR Granger Causality Tests.

\begin{tabular}{llllll}
\hline \multicolumn{2}{l}{ Dependent Variable: $\boldsymbol{K} \boldsymbol{T B}$} & \multicolumn{4}{c}{ Dependent Variable: $\boldsymbol{K P G}$} \\
\hline Excluded & $\boldsymbol{\chi}^{2}$ & Prob. & Excluded & $\boldsymbol{\chi}^{2}$ & Prob. \\
\hline FFR & 0.167 & 0.920 & FFR & 1.906 & 0.386 \\
UM2 & 3.094 & 0.213 & UM2 & 2.267 & 0.322 \\
UPG & 10.896 & 0.004 & UPG & 11.706 & 0.003 \\
KM2 & 4.213 & 0.122 & KM2 & 3.317 & 0.190 \\
EXR & 15.099 & 0.001 & EXR & 30.676 & 0.000 \\
KPG & 1.839 & 0.399 & KTB & 0.704 & 0.703 \\
All & 42.986 & 0.000 & All & 52.154 & 0.000 \\
\hline
\end{tabular}

Notes: For everything but oil price inflation, export price inflation, and economic growth rate the null is rejected, though there is some evidence about the effects of each variable on CPI inflation at 10 percent significance level.

The SVAR model's inference about the information content of external impact is drawn from the impulse responses and variance decomposition. The first source is the impulse response of domestic trade balance and output growth to the U.S. monetary shocks. Second, variance decomposition can indicate which variables have short-term and medium-term impacts on another variable of interest. This statistic represents the overall contribution of external impacts to domestic trade balance and output growth. Next, the results of the impulse response function analysis and variance decomposition are presented because our main interest is in the response of domestic trade balance and real output growth to external monetary policy shocks.

\subsection{Results of Impulse Response Function}

We trace out the time path of the impact of structural shocks on the trade balance and output growth using the SVAR recovered from the reduced form VAR. In order to identify the structural shocks of the SVAR models, short-run restrictions are imposed. Figure 2 plots the response of the variables to the U.S. monetary policy shock along with 95 percent confidence bands. Accumulate Response of trade balance to generalized one S.D. innovations \pm 2 S.E. Confidence bands are computed with a Monte Carlo simulations assuming that shocks are asymptotically normally distributed. Consider the dynamic impact of monetary policy shock: From the impulse response analysis, the U.S. monetary policy shocks had significant positive impacts on both the U.S. and Korean real output growth rate. The response of the U.S. output growth rate have three months lag, but response of Korean real output growth have nine months lag response, respectively. On the other hand, the response of the U.S. M2, exchange rate, and Korean trade balance are appeared negatively. Especially, the response of exchange rate and trade balance to the shocks appeared to have relatively greater impacts, and it almost has no time lag. But Korean trade balance is negatively affected by the U.S. 
monetary shocks lagged one month. This implies that for an open economy, due to the most direct policy transmission channels is the international capital flows and exchange rate in the short-term, the response of trade balance would appear

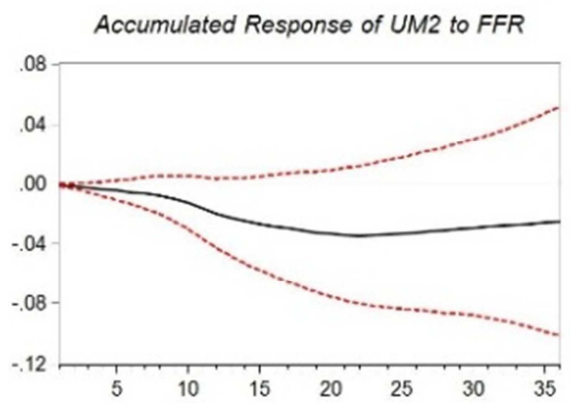

Accumulated Response of KM2 to FFR

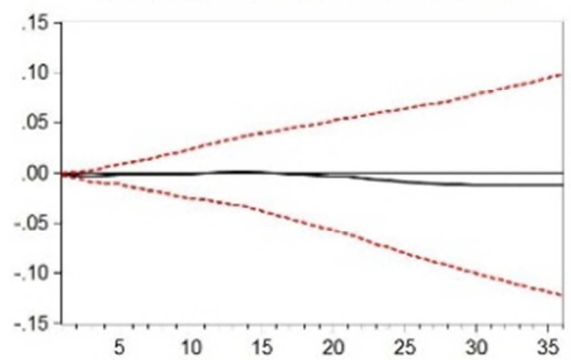

Accumulated Response of KTB to FFR

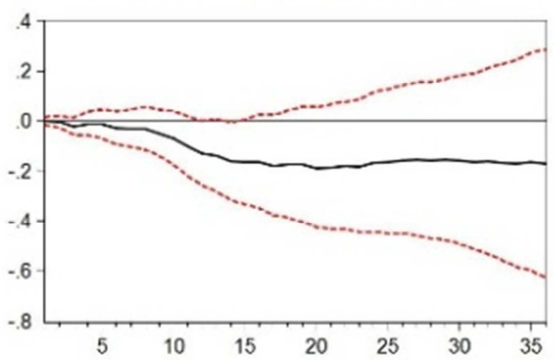

indirectly with the monetary policy shocks. So there are almost no direct responses of trade balance to the U.S. monetary policy shocks but response with the change of exchange rate.

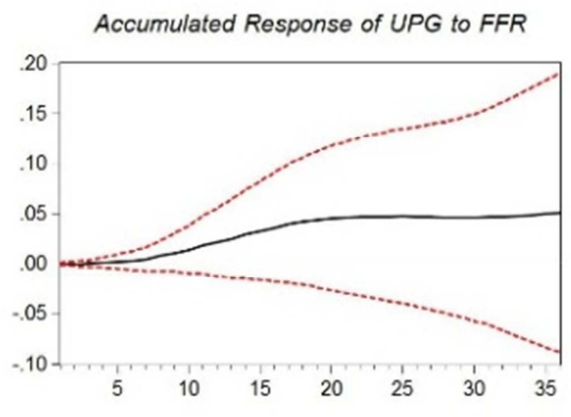

Accumulated Response of EXR to FFR

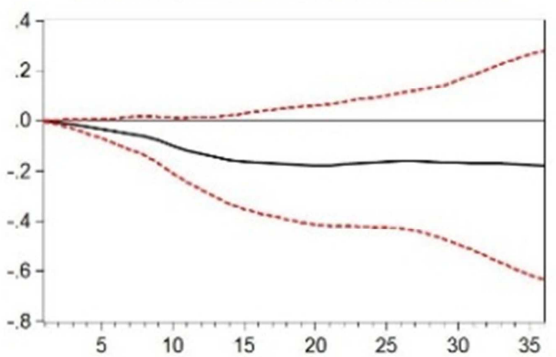

Accumulated Response of KPG to FFR

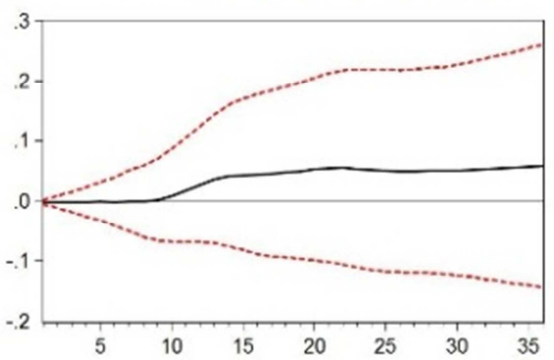

Figure 2. Responses of the Variables to the U.S. Monetary Policy Shocks.

Figure 3 plots the response of Korean trade balance to the shocks. The response of Korean bilateral trade balance to the U.S. monetary policy shocks appeared to have relatively greater negative impacts. And it also negatively affected by the growth of Korean monetary aggregate and output. On the other hand, the response of trade balance to the growth shocks of the U.S. monetary aggregate and output response are appeared positively lagged with ten to fifteen months, respectively.
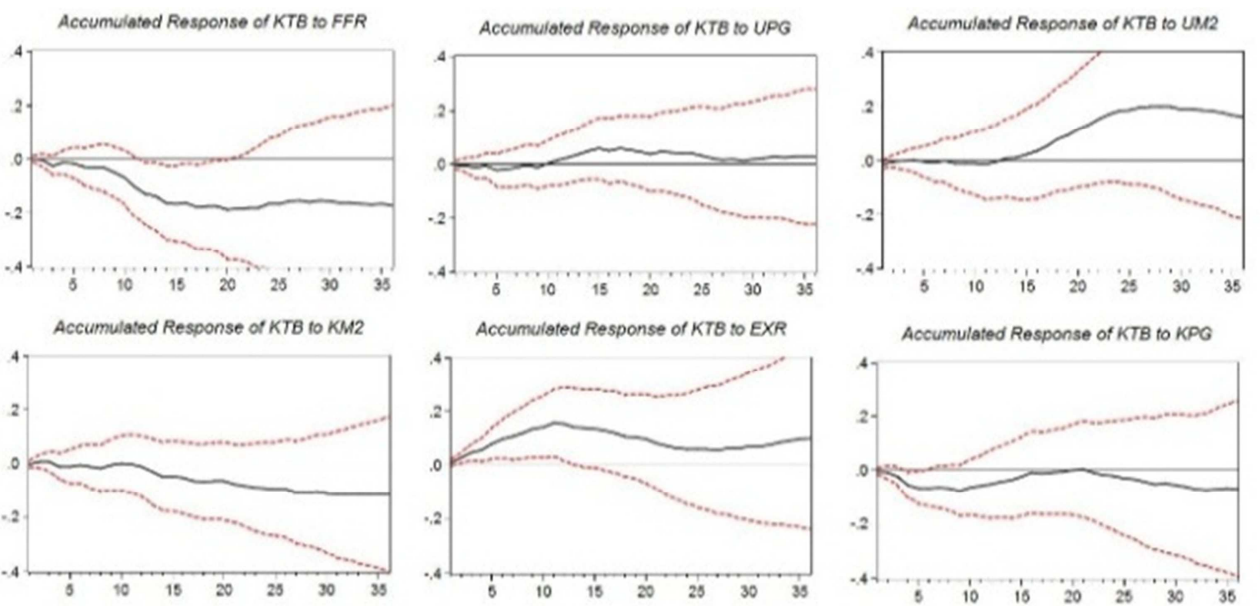

Figure 3. Responses of Trade Balance to the Shocks. 
Figure 4 show the response of Korean output growth to the shocks. The impact of the U.S. monetary policy shock on Korea's output growth directed upward from $9^{\text {th }}$ month, while that of exchange rate and Korean monetary aggregate have negative impact. The impacts of growth rates of the U.S. output, monetary aggregate and Korean trade balance were ambiguous.
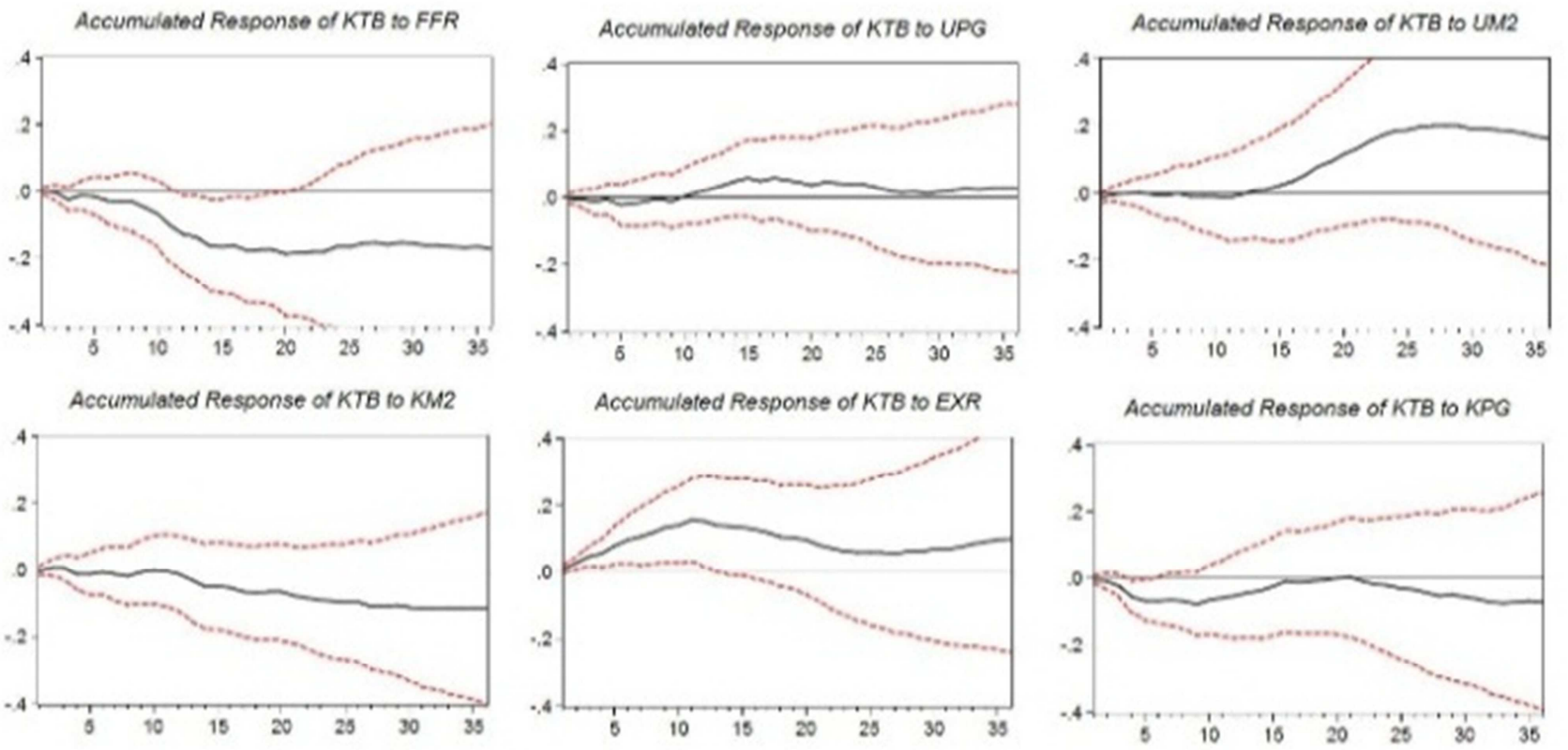

Figure 4. Responses of Output Growth to the Shocks.

\subsection{Results of Variance Decomposition}

Table 6 presents the proportionate changes in the trade balance and output growth rates that can be explained by a change in each shock at the 12 month periods only, calculated from variance decomposition using the SVAR. According to the results of variance decomposition in the monthly data, trade balance and output growth shock have the highest explanatory power over the variation of itself, which explains more than $50 \%$ of the forecast error variance especially in the short-run.

Among the external shocks, the U.S. interest rate and exchange rate shocks contribute largely to the trade balance forecast error variance, followed by the growth rate of output shocks in both domestic and foreign. Furthermore, as time passed, the part of trade balance explained by trade balance itself decreased, while the proportion explained by the U.S. interest rate, monetary aggregate, and real output increased.

More specifically, the proportion explained by the U.S. interest rate only $0.00 \%(0.49 \%)$ after one month, but sharply increased to $16.44 \%(5020 \%)$ after twelve months and the proportion of the U.S. real output is $0.15 \%(2.19 \%)$ after one month, but increased to $5.60 \%(3.25 \%)$ after twelve months in the trade balance and real output growth, respectably. Thus, the change of the U.S. monetary policy is a contributor to bilateral trade balance in Korea. It also implies that in an open economy, the changes of external monetary policy can be regarded as the important factor of bilateral trade balance and real output growth with time lags through the variations of the exchange rate.
Table 6. Forecast error variance decompositions.

\begin{tabular}{|c|c|c|c|c|c|c|c|}
\hline Period & $F F R$ & UM2 & $U P G$ & $K M 2$ & $E X R$ & $K T B$ & $K P G$ \\
\hline \multicolumn{8}{|c|}{ Trade Balance } \\
\hline 1 & 0.00 & 2.03 & 0.15 & 0.03 & 0.75 & 97.04 & 0.00 \\
\hline 2 & 0.18 & 2.61 & 0.19 & 0.69 & 4.24 & 91.85 & 0.24 \\
\hline 3 & 3.81 & 2.42 & 0.90 & 0.75 & 6.09 & 83.70 & 2.34 \\
\hline 4 & 4.20 & 2.28 & 1.45 & 3.00 & 6.86 & 73.40 & 8.81 \\
\hline 5 & 3.92 & 2.46 & 3.77 & 2.78 & 9.54 & 68.39 & 9.13 \\
\hline 6 & 5.14 & 2.59 & 3.74 & 2.90 & 11.10 & 65.64 & 8.90 \\
\hline 7 & 5.07 & 2.85 & 3.84 & 3.37 & 11.57 & 64.45 & 8.84 \\
\hline 8 & 4.83 & 3.42 & 4.25 & 3.41 & 12.22 & 62.92 & 8.95 \\
\hline 9 & 6.62 & 3.33 & 4.50 & 3.74 & 12.53 & 60.09 & 9.19 \\
\hline 10 & 8.66 & 3.32 & 5.51 & 3.64 & 12.04 & 57.69 & 9.14 \\
\hline 11 & 13.71 & 3.62 & 5.56 & 3.70 & 11.86 & 53.19 & 8.35 \\
\hline 12 & 16.44 & 3.47 & 5.60 & 4.77 & 11.27 & 50.50 & 7.95 \\
\hline \multicolumn{8}{|c|}{ Real Output } \\
\hline 1 & 0.49 & 1.83 & 2.19 & 0.70 & 0.33 & 0.52 & 93.95 \\
\hline 2 & 0.27 & 1.92 & 1.22 & 0.40 & 3.44 & 0.60 & 92.15 \\
\hline 3 & 0.20 & 1.40 & 0.92 & 0.32 & 5.74 & 0.51 & 90.91 \\
\hline 4 & 0.19 & 1.89 & 2.63 & 1.65 & 9.65 & 0.49 & 83.50 \\
\hline 5 & 0.19 & 1.79 & 2.73 & 2.33 & 11.86 & 0.45 & 80.64 \\
\hline 6 & 0.24 & 1.63 & 2.81 & 2.36 & 14.47 & 0.41 & 78.08 \\
\hline 7 & 0.32 & 1.88 & 3.31 & 2.78 & 14.50 & 0.39 & 76.83 \\
\hline 8 & 0.32 & 2.88 & 3.27 & 3.68 & 15.24 & 0.48 & 74.12 \\
\hline 9 & 0.53 & 4.12 & 3.42 & 5.22 & 14.98 & 0.67 & 71.06 \\
\hline 10 & 1.84 & 4.49 & 3.25 & 6.30 & 14.91 & 1.67 & 67.55 \\
\hline 11 & 3.76 & 4.58 & 3.35 & 6.45 & 14.45 & 2.29 & 65.13 \\
\hline 12 & 5.20 & 4.61 & 3.25 & 6.53 & 14.23 & 3.09 & 63.09 \\
\hline
\end{tabular}

\section{Conclusion}

This This study estimates the growth rates of bilateral trade balance and real output in Korea to identify the transmission effects of the U.S. monetary policy. Specifically, the SVAR impulse response and variance decomposition analyses were 
applied to determine the relative sizes of the reaction and what proportions are accounted for by external factors. The results show that Korean trade balance is negatively affected by the U.S. monetary shocks through the exchange rate channel. On the other hand, domestic real output is positively affected by the external monetary policy shocks over time. Thus the estimations of the trade balance and output growth in Korea suggest that, over the sample period, real economy in the small open economy influenced by the monetary policy shocks in the large country such as the U.S. Therefore, it is important to respond appropriately to changes in exchange rates in order to reduce unexpected negative influence due to the external shocks.

\section{Acknowledgements}

This work was supported by the National Research Foundation of Korea Grant funded by the Korean Government [NRF-2014S1A3A2044643].

\section{References}

[1] G. Amisano and C. Giannina, Topics in Structural VAR Econometrics, $2^{\text {nd }}$ ed., Springer-Verlag, Berlin, 1997.

[2] S. M. Barakchian, "Transmission of US monetary policy into the Canadian economy: A structural cointegration analysis," Economic Modelling, vol. 46, 2015, pp. 11-26.

[3] D. Bowman, J. M. Londono, and H. Sapriza, "U.S. unconventional monetary policy and transmission to emerging market economies," Journal of International Money and Finance, vol. 55, 2015, pp. 27-59.

[4] L. Christiano, M. Eichenbaum, and C. Evans, "The effects of monetary policy shocks: evidence from the flow of funds," Review of Economics and Statistics, vol. 78, 1996, pp. 16-34.

[5] D. B. Gorden, and E. M. Leeper, "The dynamic impacts of monetary policy: An exercise in tentative identification," Journal of Political Economy, vol. 102, 1994, pp. 1228-247.
[6] N. Grilli, and N. Roubini, "Liquidity models in open economies: Theory and empirical evidence," NBER Working Paper No 5313, Cambridge: National Bureau of Economic Research, 1995.

[7] S. Kim, "International transmission of U.S. monetary policy shocks: evidence from VAR's," Journal of Monetary Economics, vol. 48, 2001, pp. 339-372.

[8] S. Kim, and N. Roubini, "Exchange rate anomalies in industrial countries: A solution with structural VAR approach," Journal of Monetary Economics, vol. 45, 2000, pp. 561-586.

[9] S. H. Lee and S. Zhu, "Time-varying transmission effects of external shocks into inflation: how different is China from Korea?" China Economic Journal, vol. 9, 2016, 1-16.

[10] Z. L. Li and D. L. Liang, "Dynamic impact of American monetary policy on China's economic - An application of the SVAR model," Economic and Management Research, vol. 3, 2011, pp. 77-83.

[11] J. G. MacKinnon, "Numerical distribution functions for unit root and cointegration Tests," Journal of Applied Econometrics, vol. 11, 1996, pp. 601-618.

[12] B. Mackowiak, "External shocks, U.S. monetary policy and macroeconomic fluctuations in emerging markets," Journal of Monetary Economics, vol. 54, 2007, pp. 2512-2520.

[13] N. Mirkov, "International financial transmission of the Fed's monetary policy," International Journal of Economic Sciences and Applied Research, vol. 7, 2014, pp. 7-49.

[14] S. Neril and A. Nobili, "The transmission of US monetary policy to the Euro area," International Finance, vol. 13, 2010, pp. 55-78.

[15] C. Precious and M. K. Palesa, "Impact of monetary policy on economic growth: A case study of South Africa," Mediterranean Journal of Social Sciences, vol. 5, 2014, pp. 76-84.

[16] C. A. Sims, "Interpreting the macroeconomic time series facts: The effects of monetary policy," European Economic Review, vol. 36, 1992, pp. 975-1011.

[17] J. H. Stock and M. W. Watson, "Implications of dynamic factor models for VAR analysis," NBER Working Paper No. 11467, 2001. 